\title{
Importance of informed consent defined by General Surgery Associations in Turkey
}

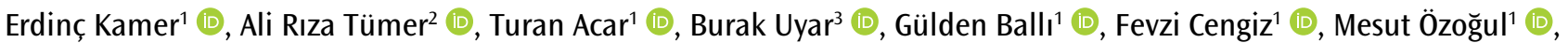
Mehmet Hacıyanlı' 1 (1)

ABSTRACT

ORCID IDs of the authors: E.K. 0000-0002-5084-5867; A.R.T. 0000-0002-0547-4868; T.A. $0000-0003-4261-2673$; B.U. 0000-0002-3178-4157; G.B. 0000-0003-3353-0270; F.C. 0000-0002-1614-5568; M.0̈. 0000-0001-6186-7124; M.H. 0000-0002-0512-1405.

\section{Cite this paper as:} Kamer E, Tümer AR, Acar T, Uyar B, Ballı G, Cengiz F, et al. Importance of informed consent defined by General Surgery Associations in Turkey. Turk J Surg 2018; 34: 97-100.

'Department of General Surgery, İzmir Katip Celebi University, Atatürk Training and Research Hospital, İzmir, Turkey

${ }^{2}$ Department of Forensic Medicine, Hacettepe University School of Medicine, Ankara, Turkey

${ }^{3}$ Department of Econometrics, Yüzüncüyll University Faculty of Economics and Administrative Science, Van, Turkey

This study was presented at the "20. National Congress of Surgery", 13-17 April 2016, Antalya, Turkey.

\section{Corresponding Author Erdinç Kamer} e-mail: erdinc.kamer@gmail.com

Received: 03.11.2016 Accepted: 20.03.2017

\section{(C) Copyright 2018} by Turkish Surgical Association Available online at www.turkjsurg.com
Objective: Informed consent is a term based on the idea that every individual has the right to know every medical intervention that is going to be performed on their own body and to learn the issues that she/he may encounter in case of refusal of intervention, and it also defines the protection of personal rights under the guarantee of law.

Material and Methods: The website of Turkish Surgical Association and 25 different websites of surgical associations were evaluated according to general surgery association guide, which was published by the Turkish Surgical Association in 2011.

Results: Four websites of those surveyed include informed consent sections and these were evaluated. A total of 44 informed consent forms were included in this study. Of these, 29 were in Turk Colon and Rectum Surgery Association, 8 were in Turkish Surgery Association, 5 were in Turk Hepatopancreaticobilier Surgery Association, and 4 were in Endocrine Surgery Association. These informed consent forms were evaluated with regard to the aforementioned criteria. The results and also the distribution according to the associations were summarized. A common feature of the informed consent forms was that all of them included the risks of the intervention/operation and complications to be carried out. On the contrary, none of them included approximate time of surgery, information about surgeons, issues that patients should care about before surgery, the section that permits the use of data for scientific purpose, and the time of signing the informed consent form.

Conclusion: We believe that in this context the regulation of informed consent by sub-specialization associations under the flag of Turkish Surgical Association is a very important matter and will standardize informed consents; websites of the associations will be easier to access, and this will be as beneficial for physicians as the patients and also will protect the physicians in probable trials.

Keywords: Association, form, importance, informed consent, surgery

\section{INTRODUCTION}

Informed consent (IC) expresses the concept in which an individual understands all medical interventions to be performed in him/her based on his/her own free choice without any external coercion, and on learning the problems to be encountered if he/she does not accept these interventions, and it also expresses the concept in which personal rights are assured with the laws regulated on this issue (1).

In the informed consent form (ICF), it is necessary that the information should be explained clearly enough for the patient to be informed so that the patient can make a decision about himself/herself. In addition, the ICF should also give the patient information which includes the benefits and risks of the recommended treatment, the alternatives to the treatment if any, and the consequences in the case that he/she rejects the treatment. In order for the consent to be valid, it is necessary for the patient to be informed about the medical intervention to be applied by the physician who will perform the treatment and to understand the information given. Based on the Article No. 70 of the Law No. 1219, only one form, which is still in practice today, is not regarded as the patient's informed consent (2). The consents received without informing are legally invalid. There are different opinions between ethics experts and legal experts regarding the amount of information to be given to the patient. While ethics experts leave the amount of information to the doctors, legal experts recommend that this level be determined by law (3). The generally accepted recommendation is that the physician who will treat the patient enlightens the patient about the medical intervention to be performed, considering the patient's physical, sociocultural and personal beliefs and values (4). There are many studies conducted on informed consent in Turkey (1-6). However, we have not encountered a study that examines the websites of associations and investigates the suitability of ICFs on these websites.

We have planned to conduct a research on whether or not the information that is required to be found in ICFs in the light of the above information is included in the informed consents published on the websites of the general surgery associations, or on how much of it is included. 


\section{MATERIAL AND METHODS}

According to the 2011 Guide of Turkish Surgical Association general surgical associations, there are a total of 26 general surgical associations, including Turkish Surgical Association in Turkey. Ethics committee approval was received for this study from the ethics committee of our hospital. One of the associations published in this guide was a federation which had 13 associations. According to this, a total of 38 internet pages have been examined. When the key words "consent" or "informed" were searched in the IC section or in the "search" button, such information could not be found in the websites of $34(89.5 \%)$ associations. IC section was found and examined in four (9.1\%) of the websites. These associations were Endocrine Surgical Association, Turkish Society of Colon and Rectal Surgery, Turkish Society of Hepato-pancreato-biliary Surgery and Turkish Surgical Association. The ICFs under the name of "general consent" that were not prepared specifically to the disease and the ICFs for colonoscopy were not included in the study. According to this, six ICFs from the Turkish Society of Colon and Rectal Surgery and one ICF from the Turkish Surgical Association were not included in the study. The criteria to be found in the informed consents were edited based on the data in the "Guide of regulations and informed consents for Physicians and Medical Chamber Executives" by a forensic medicine academician (Tümer A.R.) $(7,8)$. Number and percentage were used for the descriptive statistics.

\section{RESULTS}

IC section was found in four (9.1\%) of the websites. A total of 44 ICFs, four of which were from the website of Endocrine Surgical Association, 27 from the website of the Turkish Society of Colon and Rectal Surgery, five from the Turkish Hepato-pancreato-biliary Society and eight from the website of the Surgical Society, were included in the study. There was no part for the personal identifying information of the patients in eight (18.2\%) ICFs. In 36 of the ICFs (81.8\%), a special part was found, usually located near or below the head of the form, where the personal identifying information of the patient would be written. A box where the patient's name, surname, date of birth, gender, protocol number, scheduled surgery and the diagnoses would be written was found in four ICFs; a box where the patient's name, surname, date of birth, protocol number, the date of hospitalization, and the diagnosis would be written was found in 27 ICFs, and a box where the patient's name, surname and protocol number would be written was found just under the heading in 5 ICFs. Only six (13.6\%) of the ICFs had the information about the patient's disease, and nine (20.5\%) had the information about the surgery/intervention to be applied and a statement explaining its purpose. In all of the ICFs (100\%), there was somewhat information about the risks of the operation, and the complications-undesirable negative results. None of the ICFs had an explanation about the duration of the operation, about the doctor who would perform the surgery, about the things that the patient should be careful about before the operation, and about the permission for the data to be used in scientific studies. Five (15.9\%) of the ICFs had the points that the patients should take into consideration after the operation; five (11.4\%) of them had the information about the alternatives of the recommended treatment, if any; one of them had the information about the potential results of the recommended treatment; five (11.4\%) of them had the information about the risks that could occur if the treatment is rejected. Twenty-four (54.5\%) of the ICFs had the information about the anesthesia method to be applied in the patient (only the name is mentioned in 19 of them: such as "general anesthesia" or "local anesthesia") and the risks associated with this anesthetic method were indicated in $36(81.8 \%)$ of them. Only eight $(18.2 \%)$ of the ICFs had a section in which

Table 1. Distribution of ICFs of the associations according to the criteria

\begin{tabular}{|c|c|c|c|c|c|}
\hline & $A(n=4)$ & $B(n=8)$ & $C(n=5)$ & $D(n=27)$ & Total $(n=44)$ \\
\hline A- Personal identifying information of the patient & 4 & 0 & 5 & 27 & $36(81.8 \%)$ \\
\hline B-Information about the patient's disease & 4 & 0 & 2 & 0 & $6(13.6 \%)$ \\
\hline C-Information about the surgery/intervention to be performed and its purpose & 4 & 0 & 3 & 2 & $9(20.5 \%)$ \\
\hline D- The risks of surgery and undesired consequences/complications & 4 & 8 & 5 & 27 & $44(100 \%)$ \\
\hline E- Duration of operation & 0 & 0 & 0 & 0 & 0 \\
\hline F-Information about the doctor who will perform the operation & 0 & 0 & 0 & 0 & 0 \\
\hline G-Things the patient should pay attention to before the operation & 0 & 0 & 0 & 0 & 0 \\
\hline $\mathrm{H}$-Things the patient should pay attention to after the operation & 4 & 0 & 0 & 3 & $7(17.9 \%)$ \\
\hline I-Alternatives of the recommended treatment, if any & 0 & 1 & 4 & 0 & $5(11.4 \%)$ \\
\hline J-Potential consequences of the recommended treatment & 0 & 1 & 0 & 0 & $1(2.3 \%)$ \\
\hline $\mathrm{K}$-The risks that may arise if the treatment is rejected & 2 & 0 & 3 & 0 & $5(11.4 \%)$ \\
\hline L-Information about the anesthesia method to be applied & 4 & 3 & 0 & 17 & $24(54.5 \%)$ \\
\hline M-The risks of the anesthetic method to be applied & 4 & 6 & 0 & 27 & $37(84.1 \%)$ \\
\hline N-Permission to use the data in scientific studies & 0 & 0 & 0 & 0 & 0 \\
\hline O-The Part where the name of the patient-witness and doctor will be written & 4 & 2 & 5 & 0 & $8(18.2 \%)$ \\
\hline P- Date when informed Consent is received & 4 & 6 & 5 & 27 & $42(100 \%)$ \\
\hline Q-Time when informed Consent is received & 0 & 0 & 0 & 0 & 0 \\
\hline
\end{tabular}


the names of the patient-witness and the doctor were written. In this last part, the information of the date was indicated in 40 (\% 90.9) ICFs and the information of the time was indicated in only three (\% 6.8) of them (Table 1$)$.

\section{DISCUSSION}

Today, the ethical and legal aspects of informed consent is still being discussed by various organizations. Especially the legal regulations on IC and the corresponding sanctions are given particular importance in this discussion $(1,2,7)$. As these debates continue, there is still no consensus on the information that should be in an ICF. The Article 26 of the Ethical Rules of Medicine states that "by paying attention to the cultural, social and psychological condition of the patient, he/she should be informed about his/her health status, the diagnosis that is made, type of the recommended treatment, the success rate and duration of the treatment, the risks of the treatment for the patient's health, the use of medicines given and possible side effects, the consequences of the disease if the patient does not accept the recommended treatment, and the possible treatment options and their risks"(8). The Article 31 of the Regulations on Patient Rights, it is simply stated that "While receiving the consent, it is essential to inform the patient or his/ her legal representative about the medical intervention and its outcomes" (9). As it can be seen, there is no standardization about the information that must be found in an ICF. It has been stated in the guide prepared by the American Medical Association that the prediagnosis or diagnosis of the patient, the purpose of the recommended treatment, the risks and benefits of the recommended treatment, the alternative treatment methods if any, the benefits of the alternative treatments and their risks if any, and the natural course and risks of the disease if the patient does not accept the treatment should be included in an ideal ICF (10). The issue of adapting foreign-based ICFs to our country is another issue that needs to be discussed. However, when we examine the study of Güzeldemir, we can see that the information that must be found in a standard ICF covers the information in the guide of the American Medical Association. In the study of Güzeldemir, it is stated that a standard "Informed Consent Form" should include the diagnosis, the causes of the disease, the course of the disease, the structure and purpose of the recommended treatment or application, the duration of the anticipated intervention, the risks, complications and outcomes of the recommended treatment or application, the alternative treatment options to the recommended treatment or application, the results that the disease may cause if the recommended treatment or application is rejected, the benefits and expected results of the treatment if the recommended treatment or application is accepted, the information about the person to perform the treatment or application, and the medical fee (3). Here, the most remarkable parts are "the duration of the anticipated intervention, the person to perform the application and the medical fee". According to the study of Tümer; the points that should be included in an ICF are the diagnosis of the disease, the content of the treatment recommended to the patient, the aim of treatment and the chance of success, the risks of the recommended treatment and alternatives if any, the potential outcomes of the treatment, problems that the patient may encounter if he/she does not accept the treatment, the time required for the patient to return to normal life, the features of the drugs that the patient will use (such as duration, usage, side effects, interactions with other drugs), what the patient should do at home after treatment, how he/she will access medical aid for the same cause, personal identifying information of the person who will carry out the treatment, and his/her experiences on this subject (11-13). As is seen, considering the points that should be included in an ICF, there are differences in four studies, one of which is foreign-based.

According to the "Guide of regulations and informed consents for Physicians and Medical Chamber Executives", the information given to the patient should include the patient's diagnosis, information about health status, the recommended treatment method, the success and possible risks of this treatment method, the use and possible side effects of the given drugs, problems that the patient may encounter if he/she does not accept the treatment, alternative treatment options and the risks of these options.

Nowadays; although the importance of IC for both patient and physician has increased in the light of this information, there is not a parallel increase in the importance given to this subject. When the point of view of the general surgery associations on the fact of IC, which has been known for about 17 years, was examined, it was seen that this matter should be emphasized once again (12).

We see that the Turkish Surgical Association is an association that connects a truly great community which consists of 38 associations. The websites of most of these associations are actively working. On this site, it is possible to reach a lot of information about the association, scientific activities of the association, courses, scholarships, and links to the journals which they are affiliated to. These sub-branch associations under the Turkish Surgical Association have an effective and active role in their own branches.

It was seen that only $9.1 \%$ of these associations prepared ICFs according to their sub-branches and put them in their internet sites. Considering the diseases covered by the General Surgery and their surgical treatment, this ratio is very low. Moreover, it was seen that the ICFs that were found did not have most of the required information. The common characteristics of ICFs were that although the risks associated with the intervention/operation to be performed and the undesired negative consequences-complications were written in all of them, the approximate duration of the operation, the information about the doctor who would perform the surgery, the things that the patient should pay attention to before the operation, and permission for the use of data in scientific studies were not included in any of them. It is remarkable that the associations show a considerable indifference and insensibility about the IC, which is a really important issue in legal and humanitarian terms.

When we write "informed consent for ......... disease" in search engines independently of associations, we see dozens of different ICFs belonging to a disease. In other words, we see that individuals or organizations prepare disease-specific ICFs according to themselves. It is a matter of debate how protective the use of these non-standard or non-legal forms is against the law (13). 
On the other hand, getting only one form signed, which is still being applied today, is not regarded as the patient's informed consent $(1,12)$. It is essential that the patient should be informed in order for the consent to be valid. Today, the Constitutional Court has considered that an operation performed without the written informed consent of a person as well as an insufficient information and even the inability to prove that the patient has been informed are a violation of right (Y13.HD 2008 / 10750th Decision) (14). The physician has the burden of proof with regards to the fact that the informing has been done. It is natural that the physician assumes the burden of proof because the physician should actually have related documents and carry out the enlightenment procedure. In Ersoy's study; while most surgeons stated that they enlightened their patients, the fact that most of the patients stated that no explanation was given to them and that most of the patients had no information about the medical intervention that would be applied to them indicated that the people who would apply the medical intervention were not successful in providing the necessary amount of information and understanding (4).

\section{CONCLUSION}

Briefly, "Informed consent" is the process in which the patient gives the authority to use the medical facilities to the physician who will apply the treatment as the case may be, as a result of the formation of a human relationship between the patient who will be treated and the health worker who will perform the treatment.

A standard ICF should certainly include the parts of patient's personal identifying information (name, surname, protocol number, phone number), the diagnosis of the disease, information about the disease, information about the surgery/ intervention to be performed and its purpose, the risks of operation/intervention and undesired negative consequences-complications, approximate duration of the surgery, information about the doctor who will perform the surgery, the things that the patient should pay attention to before and after the operation, the risks that the patient may encounter if he/she does not accept the treatment, information about the anesthetic method to be applied, the risks of the anesthetic method to be applied, permission for the use of data in scientific studies. In the last part of the ICF, the name and surname of the patient, the name and surname of the witness and the name and surname of the doctor who gives the information, and the date and time when the information was given should certainly be included.

All information in the ICF should be explained in accordance with the sociocultural level of the patient.

In lawsuits commenced for compensation by the patient and/or relatives, the fact that the patient is not sufficiently informed, that an appropriate IC is not received or the lack of IC put the physician in a difficult position before the law. In this context, we believe that the proper arrangement and publication of ICFs by sub-branch associations under the roof of
Turkish Surgical Association will provide sufficient information about the procedure to the patient, protect the physicians in possible lawsuits and bring a standardization to this issue.

Ethics Committee Approval: Ethics committee approval was received for this study from the ethics committee of İzmir Katip Çelebi University, Atatürk Training and Research Hospital.

Informed Consent: Not required in this study.

Peer-review: Externally peer-reviewed.

Author Contributions: Concept - E.K., A.R.T., M.H.; Design - E.K., G.B.; Supervision - A.R.T., M.H.; Resource - T.A., F.C.; Materials - E.K.,T.A., F.C.; Data Collection and/or Processing - E.K., B.U., G.B.; Analysis and/or Interpretation - E.K., B.U., G.B.; Literature Search - E.K., T.A., M.Ö.; Writing Manuscript - E.K., A.R.T.; Critical Reviews - A.R.T., M.H.

Conflict of Interest: The authors have no conflicts of interest to declare.

Financial Disclosure: The authors declared that this study has recevied no financial support.

\section{REFERENCES}

1. Tümer AR, Karacaoğlu E, Akçan R. Problems related to informed consent in surgery and recommendations Turk J Surg 2011; 27: 191-197.

2. Gülhan Y. Bilgilendirme ve Bilgilendirilmiş Onam, 4.Hastane Yönetimi Sempozyumu 27-28 Eylül 2001. (http://www.sabem. saglik.gov.tr/kaynaklar/690_2bilgilendirilmis_onam.pdf)

3. Güzeldemir ME. Hasta bilgilendirmenin önemi. Sendrom Tıp Dergisi 2005; 1-28.

4. Ersoy N. Aydınlatılmış Onam, Çağdaş Tıp Etiği, Edit. A.D. Erdemir, Ö. Öncel, Ş. Aksoy. Nobel Tıp Kitapevleri 2003; 204-30.

5. Yiğit T, Makay Ö, İçöz G, Akyıldız M. How informed are endocrine surgery patients about the risks of surgery after approving an informed consent? Turk J Surg 2014; 30: 93-96. [CrossRef]

6. Sarı I, Aşırdizer M. The concept of "consent in children" in medical applications and scientific studies J For Med 2014; 28: 60-72.

7. Grady C. Enduring and emerging challenges of informed consent N Engl J Med 2015; 372: 855-862. [CrossRef]

8. Hekimlik Meslek Etiği Kuralları. Available from: URL: http://www. ttb.org.tr/mevzuat/index.php?option=com_content\&task=view \&id $=65 \&$ ltemid $=31$.

9. Hasta Hakları Yönetmeliği. Available from: URL: http://www.mevzuat.adalet.gov.tr/html/20267.html.

10. Leclercq WK, Keulers BJ, Scheltinga MR, Spauwen PH, van der Wilt GJ. A review of surgical informed consent: past, present, and future. A quest to help patients make better decisions World J Surg 2010; 34: 1406-1415. [CrossRef]

11. Hekimler ve Tabip odası yöneticileri için mevzuat aydınlatılmış Onam Kılavuzu. Bilgilendirme süreci bölümü. Available from: URL: http://www.ttb.org.tr/mevzuat

12. Özlü T. Aydınlatılmış onam formları nasıl olmalı? Available from: URLL: http://www.medimagazin.com.tr/authors/tevfik-ozlu/traydinlatilmis-onam-formlari-nasil-olmali-72-45-671.html.

13. Tümer AR. Kolorektal kanserlerde "hasta bilgilendirilmesi ve onam. Available from: URL: http://www.tkrcd.org.tr/KolonRektumKanserleri/013_tumer.pdf.

14. Işık Yılmaz ŞB. The obligation of informing the physician of medical intervention TTB dergisi 2012; 98: 389-410. 